\title{
Welcome to the 13th volume of Biomarkers in Medicine
}

\author{
Ebony Torrington ${ }^{1}$ \\ ${ }^{1}$ Future Science Group, Unitec House, 2 Albert Place, London N31QB, UK
}

First draft submitted: 12 November 2018; Accepted for publication: 12 November 2018; Published online: 18 December 2018

\section{Background}

To all of our readers, we would like to welcome you to volume 13 of Biomarkers in Medicine. We are pleased to introduce the first issue of 2019. In this foreword we will present some highlights from the last 12 months in addition to looking forward to the year ahead.

We are very excited to announce that this year the number of issues published per volume for Biomarkers in Medicine will increase. Previously, the journal published 12 issues per year; however, as Biomarkers in Medicine continues to grow and the audience expands we have decided to increase the number to 18 .

We would also like to take this opportunity to thank all of our valued editorial board members, readers, authors and peer reviewers for their continued support; we very much look forward to seeing the journal progress and develop as we move into 2019.

\section{Content highlights}

The top five most read articles of the past year are shown in Table 1; these articles demonstrate the diverse research that is being done in the field, as well as some of the key focus areas. At the time of writing, our most read article of 2018 was an editorial titled 'Biomarkers in chimeric antigen receptor T-cell therapy' [1]. In this article W Kong and co-authors from University of Pennsylvania (PA, USA), outline the importance of biomarkers for the treatment of cancers with chimeric antigen receptor T-cell therapy.

Another highly popular editorial and one of our top-scoring articles on the Altmetric platform [2] this year outlined biomarkers for assessing the effectiveness of immunotherapy in breast cancer [3]. The authors summarize PD-L1 expression and tumor-infiltrating lymphocyte assessment in triple negative breast cancer tumors as a biomarker for treatment with immune checkpoint inhibitors.

Our most read perspective in 2018 is titled 'A peripheral blood transcriptome biomarker test to diagnose functional recovery potential in advanced heart failure' and authored by MC Deng, University of California (CA, USA) [4]. The work discusses the use of leukocytes as a predictive biomarker to diagnose functional recovery potential for advanced heart failure patients pretreatment.

Special mention goes to the following articles, which have achieved the highest Altmetric scores in the journal during 2018, as we continue our successful partnership with the platform:

- Our highest scores were for the 'TK1 as a tumor biomarker, technical advances offer new potential to an old biomarker' [ 6 mentioned by two news outlets and on twitter and ' $\alpha$-2-macroglobulin in Alzheimer's disease: new roles for an old chaperone' also mentioned on Twitter and by a news outlet [7];

- An editorial that scored highly was an article by Nixon and colleague, 'Biomarkers for assessing the effectiveness of immunotherapy in breast cancer' [3];

- We also received high scores for a review article discussing the 'Diagnostic and prognostic role of semantic processing in preclinical Alzheimer's disease' [8].

\section{Readership demographics}

As the biomarker research community continues to grow, the readership of Biomarkers in Medicine changes. In 2018, we saw an increase in our content being read by experts in the USA (39\%) and Europe (37\%) compared with 2017 (Figure 1) [9]. While our content continues to have impact across Europe and the West, we expect to 


\begin{tabular}{|c|c|c|c|c|}
\hline Rank & Title & Author(s) & Volume (issue) & Ref. \\
\hline 1 & Biomarkers in chimeric antigen receptor T-cell therapy & W Kong, SF Lacey, JJ Melenhorst, JA Fraietta & Volume 12 (Issue 5) & [1] \\
\hline 2 & $\begin{array}{l}\text { Biomarkers for assessing the effectiveness of } \\
\text { immunotherapy in breast cancer }\end{array}$ & MJ Nixon, JM Balko & Volume 12 (Issue 2) & [3] \\
\hline 3 & $\begin{array}{l}\text { A peripheral blood transcriptome biomarker test to } \\
\text { diagnose functional recovery potential in advanced } \\
\text { heart failure }\end{array}$ & MC Deng & Volume 12 (Issue 6) & [4] \\
\hline 4 & $\begin{array}{l}\text { The increase in copeptin levels in mild head trauma does } \\
\text { not predict the severity and the outcome of brain } \\
\text { damage }\end{array}$ & LM Castello, L Salmi, I Zanotti, et al. & Volume 12 (Issue 6) & [5] \\
\hline 5 & $\begin{array}{l}\text { Thymidine kinase } 1 \text { as a tumor biomarker: technical } \\
\text { advances offer new potential to an old biomarker }\end{array}$ & KK Jagarlamudi, M Shaw & Volume 12 (Issue 9) & [6] \\
\hline
\end{tabular}

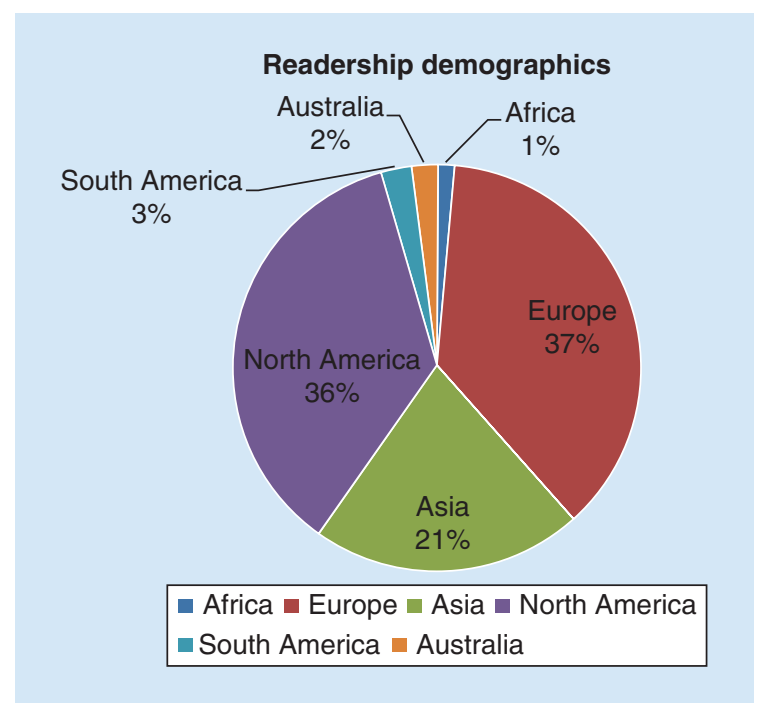

Figure 1. Readership demographics for Biomarkers in Medicine in 2018.

see a continued growth in emerging scientific communities and look forward to continuing the circulation of our content to an increasingly global audience.

\section{Social media}

Biomarkers in Mediciness social media presence has continued to grow throughout 2018 and you can join over 1000 people (at the time of writing) in following the journal on Twitter, at @fsgbmm [10]. We regularly post journal highlights, including newly published content and issues, offers and the latest news in the field.

\section{Conclusion}

We appreciate all feedback from biomarker communities regarding the direction of our content, especially suggestions of any priority topics in the field that you feel the journal should cover. We welcome unsolicited research, review and opinion article proposals, among others and would be delighted to hear from you if you are interested in submitting to the journal.

Financial \& competing interests disclosure

E Torrington is an employee of Future Medicine Ltd., publisher of Biomarkers in Medicine. The author has no other relevant affiliations or financial involvement with any organization or entity with a financial interest in or financial conflict with the subject matter or materials discussed in the manuscript apart from those disclosed. This includes employment, consultancies, honoraria, stock ownership or options, expert testimony, grants or patents received or pending, or royalties.

No writing assistance was utilized in the production of this manuscript. 


\section{References}

1 Kong W, Lacey S, Melenhorst J, Fraietta J. Biomarkers in chimeric antigen receptor T-cell therapy. Biomark. Med. 12(5), 415-418 (2018).

2 Altmetric. Altmetric Explorer. (2018). www.altmetric.com

3 Nixon M, Balko J. Biomarkers for assessing the effectiveness of immunotherapy in breast cancer. Biomark. Med. 12(2), 97-100 (2018).

4 Deng M. A peripheral blood transcriptome biomarker test to diagnose functional recovery potential in advanced heart failure. Biomark. Med. 12(6), 619-635 (2018).

5 Castello L, Salmi L, Zanotti I et al. The increase in copeptin levels in mild head trauma does not predict the severity and the outcome of brain damage. Biomark. Med. 12(6), 555-563 (2018).

6 Jagarlamudi K, Shaw M. Thymidine kinase 1 as a tumor biomarker: technical advances offer new potential to an old biomarker. Biomark. Med. 12(9), 1035-1048 (2018).

7 Seddighi S, Varma V, Thambisetty M. $\alpha 2$-macroglobulin in Alzheimer's disease: new roles for an old chaperone. Biomark. Med. 12(4), 311-314 (2018).

8 Venneri A, Jahn-Carta C, De Marco M, Quaranta D, Marra C. Diagnostic and prognostic role of semantic processing in preclinical Alzheimer's disease. Biomark. Med. 12(6), 637-651 (2018).

9 Tarring A. Biomarkers in Medicine: foreword. Biomark. Med. 12(1), 1-3 (2018).

10 Twitter. Biomarkers in Med Jnl (@fsgbmm). (2018). www.twitter.com/fsgbmm 
